\title{
Effect of ethrel in aqueous solution and ethylene released from ethrel on guava fruit ripening
}

\author{
Ibtissam Abdalla Mohamed-Nour and Abu-Bakr Ali Abu-Goukh
}

\author{
Department of Horticulture, Faculty of Agriculture, University of Khartoum, \\ Shambat, 13314, Sudan \\ Corresponding author: Abu-Bakr Ali Abu-Goukh, phone number +249-912148700, \\ E-mail: aabugoukh@uofk.edu; aabugoukh@yahoo.com \\ ABSTRACT
}

\begin{abstract}
The effect of ethrel in aqueous solutions at 250,500 and $1000 \mathrm{ppm}$ and ethylene released from ethrel at 250, 500 and 1000 ppm was evaluated on fruit ripening of white- and pink-fleshed guava fruits. Ripening was enhanced in all treated fruits of both guava types at all concentrations used. The ripening rate progressively increased with increase in concentration. Ethylene released from ethrel was more effective in triggering fruit ripening than dipping fruits in aqueous solution of ethrel. Depending on concentration, ripening was 2-6 days faster in fruits dipped in aqueous solutions of ethrel and 6-9 days earlier in fruits treated with ethylene released from ethrel, compared with untreated fruits. The effect on fruit ripening was indicated by enhanced climacteric peak of respiration, increased peel color, increased total soluble solids and decreased flesh firmness.
\end{abstract}

\section{Keywords: Guava, ethylene, ethrel, fruit ripening INTRODUCTION}

Guava (Psidium guajava L.) is a popular fruit crop in Sudan and is commercially grown in every state. The fruit is delicate and cannot withstand long-distance transportation and may reach the market in a mushy, over-ripe state. It can store well only for few days at ambient conditions. Due to the delicate nature of the fruit, it should be picked mature-green and ripened afterwards.

The use of ethylene gas in achieving faster and more uniform ripening of fruits is well documented (Kader, 2002). Many scientists duplicated the effects of ethylene gas by use of aqueous solutions of ethrel (2chloroethyl phosphonic acid). Ripening is promoted in many harvested fruits by dipping in 500 to $2000 \mathrm{ppm}$ ethrel in aqueous solution (EI Rayes, 2000; Ibrahim et al, 1994; Mohamed and Abu-Goukh, 2003). Ethrel has the disadvantage of having to be applied to fruits in aqueous solution, an extra step in handling which increases cost and enhances spread of disease (Pantastico et al, 1975). In the presence of alkaline medium ethylene evolves from ethrel (Thompson and Seymour, 1982). Commodities can be treated with ethylene gas liberated from ethrel in an alkaline medium to promote fruit ripening (Mohamed and Abu-Goukh, 2003). A calculated amount of ethrel $(200 \mathrm{ml})$ of active ingredient if added to enough sodium hydroxide, will allow the release of about 28 thousand cubic centimeters of ethylene gas (Kader,
2002). Mohamed and Abu-Goukh (2003) reported that ethylene released from ethrel was more effective in triggering fruit ripening in three mango cultivars than dipping fruits in aqueous solution of ethrel.

This study was carried out to evaluate the effect of ethrel in aqueous solution and ethylene gas liberated from ethrel in an alkaline medium on guava fruit ripening.

\section{MATERIALS AND METHODS}

Experimental Material: Mature-green fruits of whiteand pink- fleshed guava fruits were obtained from an orchard at Al-Kadaro, Khartoum North (Lat. $15^{\circ} 40^{\prime} \mathrm{N}$, long. $32^{\circ} 22^{\prime} \mathrm{E}$ ). Fruits were selected for uniformity of size, color and freedom from blemishes. The fruits were washed, air dried and transported to the experimental laboratory.

Fruit Treatment: The fruits, of each of the two guava fruit types, were distributed among the seven treatments in a randomized complete block design with four replications. Ethrel treatments were applied by dipping the fruits for $3 \mathrm{~min}$ in ethrel aqueous solutions of 250,500 or $1000 \mathrm{ppm}$ and air dried. The untreated (control) fruits and the ethrel-treated ones were kept in closed 4-litres metal cans. Treatment with ethylene released from ethrel was carried out in similar cans after the free space volume of each was determined. The fruits and a beaker containing $15 \mathrm{ml}$ of $40 \%$ sodium hydroxide $(\mathrm{NaOH})$ were put in each 
can. Calculated amounts of ethrel that would release ethylene gas of 250,500 or $1000 \mathrm{ppm}$ were added quickly to the beaker of $\mathrm{NaOH}$ and the cans were immediately closed. All cans were opened 24 hours later. Fruits were ripened at $20 \pm 1^{\circ} \mathrm{C}$ and $85-90 \%$ relative humidity.

Respiration rate: Respiration rate was determined daily during the ripening period on 15 fruits in each treatment in a flowing system by total absorption method and expressed in $\mathrm{mg} \mathrm{CO}_{2}$ per $\mathrm{kg}-\mathrm{hr}$ (Bashir, 1999). About $2.0 \mathrm{~kg}$ of fruits were put in the respiration chamber equipped with an inlet and outlet. A constant air flow was passed though $40 \% \mathrm{NaOH}$ (to absorb atmospheric $\mathrm{CO}_{2}$ ), distilled water (to absorb any $\mathrm{NaOH}$ fumes and to humidify the air) and through the respiration chamber. $\mathrm{CO}_{2}$ of respiration was trapped in $50 \mathrm{ml}$ of $0.1 \mathrm{~N} \mathrm{NaOH}$ for $1 \mathrm{hr} .15 \mathrm{ml}$ of $\mathrm{NaOH}$ solution (containing $\mathrm{CO}_{2}$ of respiration) were titrated with $0.1 \mathrm{HCl}$ using mixed indicator to whitish-yellow end point. Methyl orange indicator was added and titration was proceeded to pink color end point. The acid used for the second titration $\left(V_{2}\right)$ is equivalent to half the total carbonate.

Calculations: Milliequivalent of carbonate (meq.) $=2 \mathrm{~V}_{2} \cdot \mathrm{N} \mathrm{HCl}$. Equivalent weight of carbonate $=$ Formula Wt./ Charge $=106 / 2$ $=50$.

Wt. of $\mathrm{Na}_{2} \mathrm{CO}_{3}=$ (meq. of $\mathrm{Na}_{2} \mathrm{CO}_{3}$ ) (Eq. Wt. of $\mathrm{Na}_{2} \mathrm{CO}_{3}$ ). Wt. of $\mathrm{CO}_{2}$ absorbed $=(44 / 106)$ (Wt. of $\mathrm{Na}_{2} \mathrm{CO}_{3}$ ) (Dil. Factor). Dil. Factor $=50 / 15$.

Respiration Rate $(\mathrm{mg} \mathrm{CO} / \mathrm{kg}-\mathrm{hr})=\left[\mathrm{Wt}\right.$. of $\mathrm{CO}_{2}$ absorbed $\left.(\mathrm{mg})\right] /$ [Sample Wt(kg). Duration (hr)].

Peel color changes: Peel color changes were determined daily on the same 15 fruits used for respiration in each treatment. The color score used: mature-green $(=0)$, trace yellow on skin $(=1), 20 \%$ yellow $(=2), 40 \%$ yellow $(=3), 60 \%$ yellow $(=4)$, $80 \%$ yellow $(=5)$ and $100 \%$ yellow $(=6)$.

Fruit Flesh Firmness: Flesh firmness was determined on three fruits picked randomly from each treatment, other than those used for respiration rate and color changes, at 2-day intervals during ripening. Flesh firmness was measured by Magness and Taylor firmness tester (D. Ballauf Meg. Co) equipped with $8 \mathrm{~mm}$ diameter plunger tip. Two readings were taken from opposite sides on each fruit after the peel was removed. Flesh firmness was expressed in kilograms per square centimeters.

Total soluble solids: Total soluble solids (TSS) were determined at 2-day intervals on the same fruits as used for determining flesh firmness. TSS were determined directly from the fruit juice, using a Kruss hand refractometer (model $\mathrm{HRN}-32$ ). Two readings were taken from each fruit and the mean values were calculated and corrected according to the refractometer chart.

Statistical Analysis: Analysis of variance (Gomez and Gomez, 1984), followed by Fisher's protected LSD test with a significance level of $P \leq 0.05$ were performed on the data.

\section{RESULTS AND DISCUSSION}

Ethrel in aqueous solution and ethylene released from ethrel triggered fruit ripening in both guava types at all concentration used; the higher the concentration, the higher the ripening rate. The effect on fruit ripening was indicated by enhanced climacteric peak, increased peel color, increased total soluble solids and decreased flesh firmness.

Effect on respiration rate: The rate of $\mathrm{CO}_{2}$ production, during ripening of both guava types exhibited a typical climacteric pattern of respiration. Respiration rate was significantly higher in the pink guava fruits, with a climacteric peak at $40.3 \mathrm{mg} \mathrm{CO} 2 /$ $\mathrm{kg}-\mathrm{hr}$ compared to the white ones, with peak at 32.3 $\mathrm{mg} \mathrm{CO} / \mathrm{kg}-\mathrm{hr}$. (Figs. 1 \& 2). Similar climacteric maxima in respiration were observed during ripening of guava fruits (Abu-Goukh and Bashir, 2003; Bashir and Abu-Goukh, 2003).

The untreated fruits had reached the climacteric peak after 14 days in the white and 15 days in the pink guava types. Fruits treated by dipping in aqueous solution of ethrel at 250, 500 and $1000 \mathrm{ppm}$ reached the climacteric peak 2-3, 4 and 6 days earlier than the untreated fruits, respectively. While the fruits treated with ethylene released from ethrel at 250, 500 and $1000 \mathrm{ppm}$ had reached the climacteric peak 6,7 and 9 days earlier than the untreated fruits, respectively (Figs. $1 \& 2$ ). This is in agreement with earlier reports (Pratt and Goeschi, 1969; Mohamed and Abu-Goukh, 2003). Ethylene released from ethrel was more effective in triggering the climacteric than dipping fruits in the aqueous solution of ethrel. Fruits treated with ethylene released from ethrel reached their climacteric peak 3 days earlier than fruits dipped in aqueous solution of ethrel at all concentrations. Fruits treated with ethylene at $250 \mathrm{ppm}$ were similar to those dipped in aqueous solution of ethrel at 1000 ppm (Figs.1 \& 2). Ethylene gas was reported to be many folds more effective than ethrel in aqueous solution (Ibrahim et al, 1994; Russo et al, 1968). 


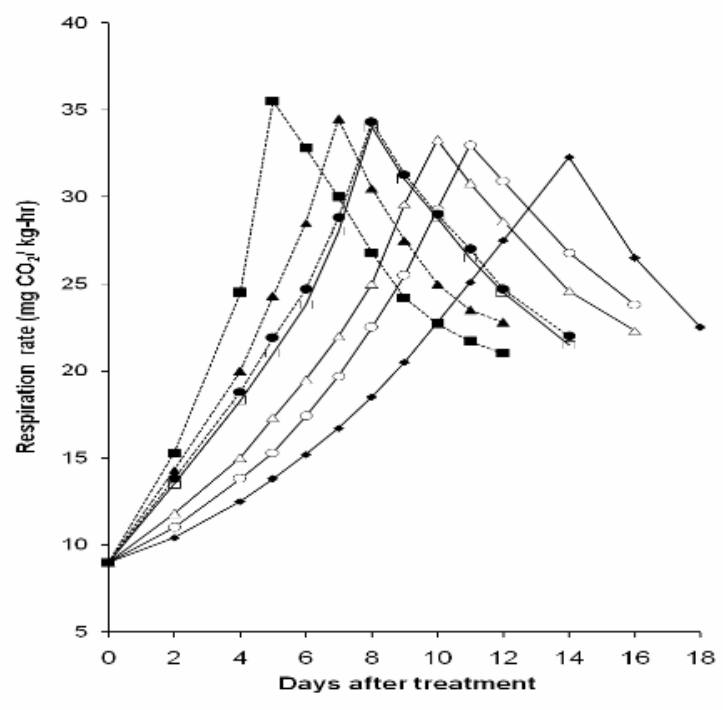

Fig. 1. Respiration rate during ripening of white guava fruits treated with ethrel in aqueous solution ( ) at 250 (o),

$500(\Delta)$ and $1000 \mathrm{ppm}(\square)$ or with ethylene released from ethrel (------) at $250(\bullet), 500(\Delta)$ and 1000 ppm (घ), compared with untreated fruits $(\diamond)$ at $20 \pm 1^{\circ} \mathrm{C}$ and 85$90 \%$ relative humidity.

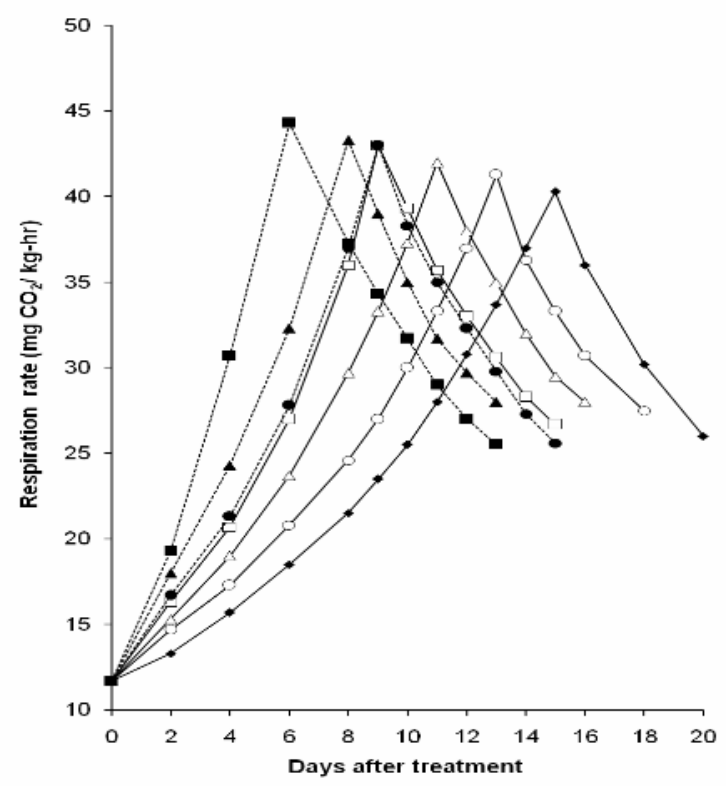

Fig. 2. Respiration rate during ripening of pink guava fruits treated with ethrel in aqueous solution ( ) at 250 (o), $500(\Delta)$ and $1000 \mathrm{ppm}(\square)$ or with ethylene released from ethrel (------) at $250(\bullet), 500(\Delta)$ and 1000 ppm (घ), compared with untreated fruits $(\triangleleft)$ at $20 \pm 1^{\circ} \mathrm{C}$ and 85 $90 \%$ relative humidity.
Effect on peel color: Peel color score progressively increased during ripening of both guava types. The untreated white and pink guava fruits reached the full yellow stage (color score 6) in 14 and 15 days, respectively (Figs. 3 \& 4). Ethrel and ethylene treatments enhanced color development in both fruit types. Fruits dipped in aqueous solution of ethrel at 250,500 and $1000 \mathrm{ppm}$ reached the full yellow stage 3,4 and 6 days earlier than the untreated fruits, respectively. Fruits treated with ethylene liberated from ethrel at 250, 500 and $1000 \mathrm{ppm}$ reached the full yellow stage 6,7 and 9 days earlier than the untreated fruits, respectively (Figs. $3 \& 4$ ).

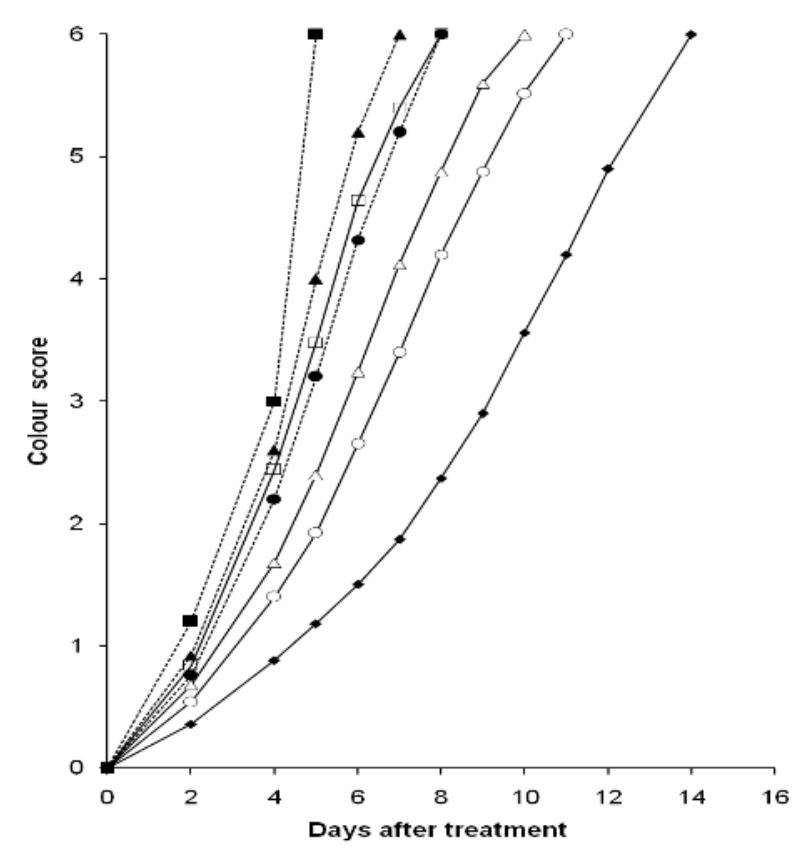

Fig. 3. Changes in peel colour during ripening of white guava fruits treated with ethrel in aqueous solution at $250(0), 500(\Delta)$ and 1000 ppm ( $\square$ ) or with ethylene released from ethrel (------) at $250(\bullet), 500(\boldsymbol{\Delta})$ and 1000 $\operatorname{ppm}(\boldsymbol{\Xi})$, compared with untreated fruits $(\diamond)$ at $20 \pm 1^{\circ} \mathrm{C}$ and $85-90 \%$ relative humidity. 


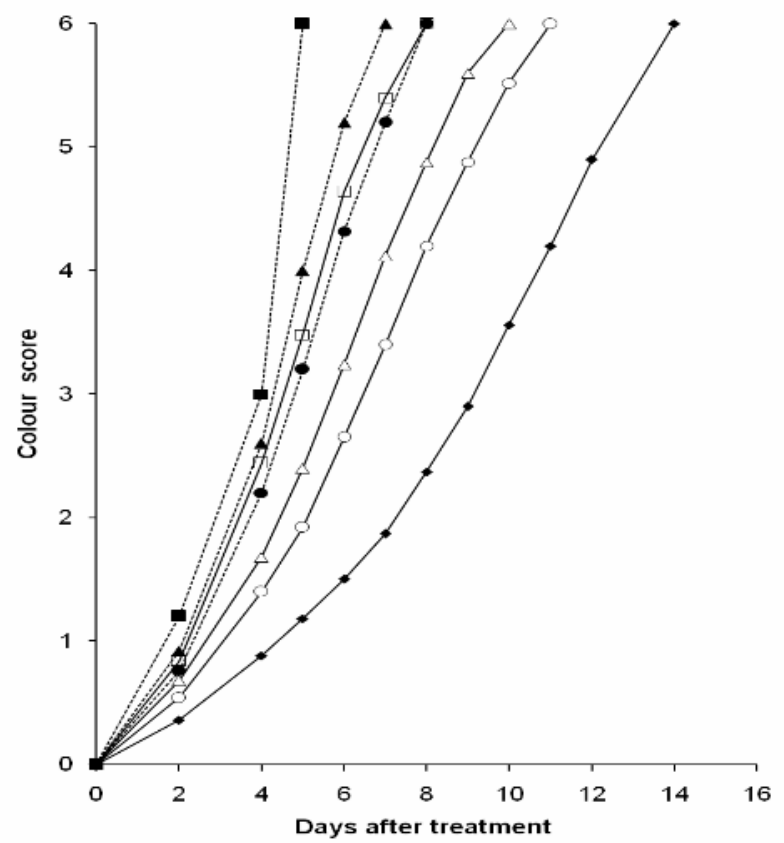

Fig. 4. Changes in peel colour during ripening of pink guava fruits treated with ethrel in aqueous solution (

at 250 (o), $500(\Delta)$ and $1000 \mathrm{ppm}(\square)$ or with ethylene released from ethrel (------) at $250(\bullet), 500(\Delta)$ and 1000 ppm (๘), compared with untreated fruits $(\bullet)$ at $20 \pm 1^{\circ} \mathrm{C}$ and $85-90 \%$ relative humidity.

Color development induced by applied ethylene and ethylene releasing compounds has been demonstrated to be through reduction in chlorophyll concentration and increase in carotenoid pigments. Ethrel was reported to hasten chlorophyll degradation in many fruits, including banana (Rao et al, 1971), mango (Ashwani et al, 1995) and orange (Azab and Ismail, 1994). The link between ethylene action and carotenoid level was well recognized (Stewart and Wheaton, 1972; Lakshminarayana et al, 1975). Yamauchi et al (1997) related the acceleration of chlorophyll degradation by ethylene treatment, to the enhancement of chlorophyllide which is formed by the action of chlorophyllase. El Rayes (2000) reported that ethrel treatment increased markedly skin color, skin carotenoids, TSS, vitamin C and fruit juice. In addition, ethrel application reduced peel chlorophyll and juice acidity. The higher the concentration of ethrel applied, the lower the chlorophyll content in fruit rind, the higher the carotenoids, TSS, vitamin C and juice content.

Effect on flesh firmness: Fruit flesh firmness of the two guava types had showed a progressive decline during ripening. The decline in flesh firmness observed in the untreated fruits was about 15-folds, from the hard mature-green stage $\left(2.17 \mathrm{kg.} \mathrm{cm}^{-2}\right.$ shear resistance) to the final soft ripe stage $(0.14 \mathrm{~kg}$. $\mathrm{cm}^{-2}$ ). This was reached in 16 days in both guava types (Figs. $5 \& 6$ ). Similar drop in guava fruit firmness was reported (Abu-Goukh and Bashir, 2003; Bashir and Abu-Goukh, 2003; Rodriguez et al, 1971).

Guava fruits treated with ethrel in aqueous solution had reached the final soft stage 2-6 days earlier, while those treated with ethylene released from ethrel had reached that final soft stage 6-9 days earlier, compared to the untreated fruits (Figs. $5 \& 6$ ). It was reported that post-harvest treatment with ethrel promoted ripening of mango fruits, and the treated fruits were less firm than the treated ones (Mohamed and Abu-Goukh, 2003; Pal, 1988).

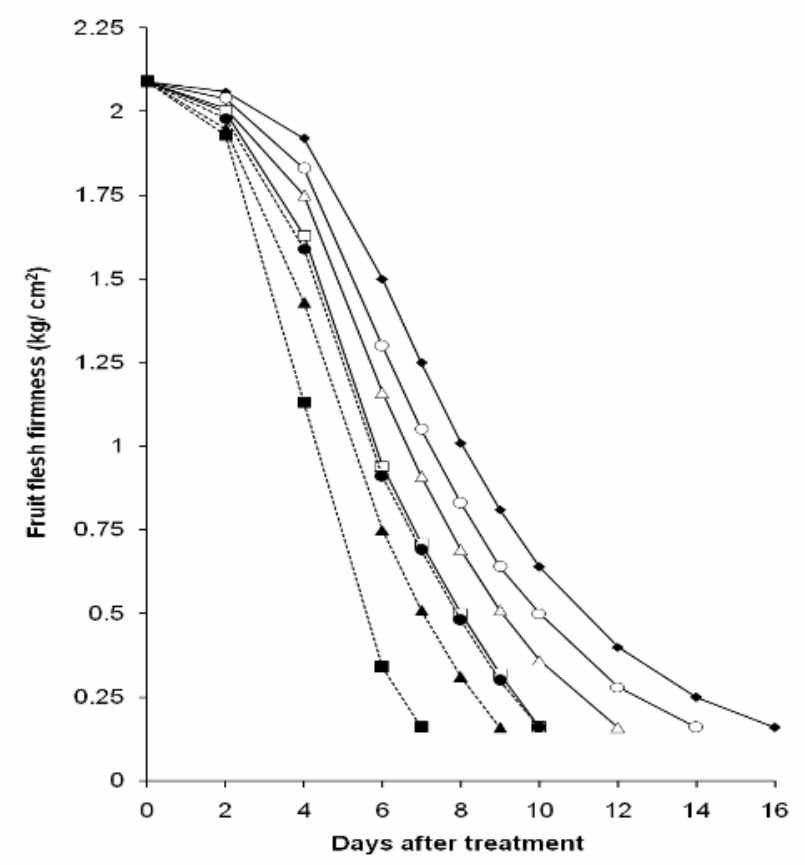

Fig. 5. Changes in fruit flesh firmness during ripening of white guava fruits treated with ethrel in aqueous solution ( ) at $250(0), 500(\Delta)$ and $1000 \mathrm{ppm}$ (口) or with ethylene released from ethrel (------) at $250(\bullet), 500(\mathbf{\Delta})$ and $1000 \mathrm{ppm}(\mathbf{\bullet})$, compared with untreated fruits $(\bullet)$ at 20 $\pm 1^{\circ} \mathrm{C}$ and $85-90 \%$ relative humidity. 


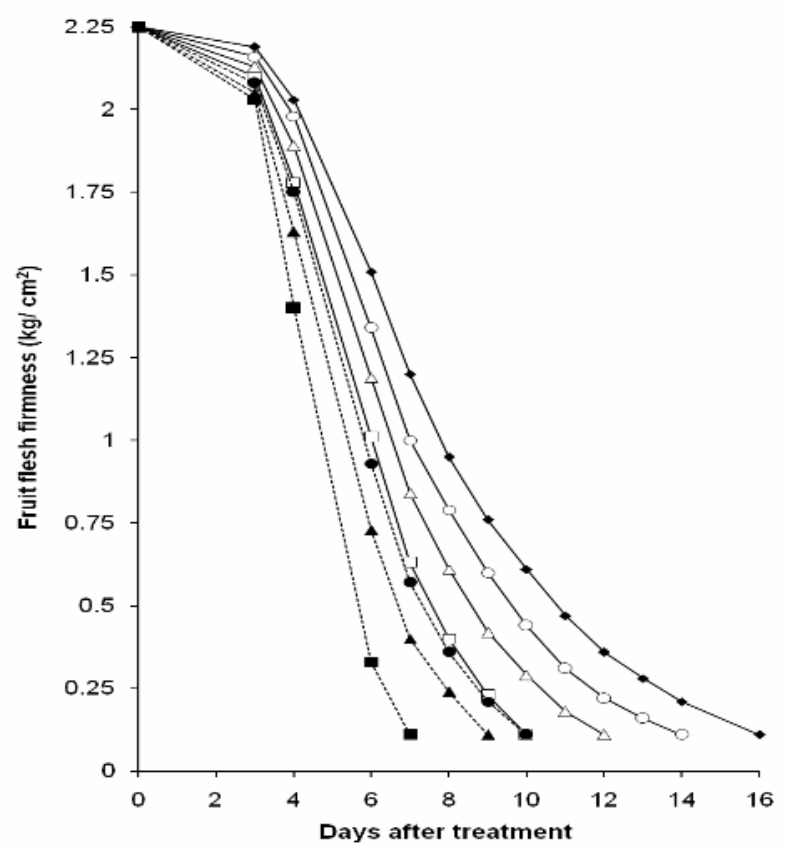

Fig. 6. Changes in fruit flesh firmness during ripening of pink guava fruits treated with ethrel in aqueous solution ( ) at $250(0), 500(\Delta)$ and 1000 ppm ( $\square$ ) or with ethylene released from ethrel (-----) at $250(\bullet), 500(\boldsymbol{\Delta})$ and $1000 \mathrm{ppm}(\mathbf{\square})$, compared with untreated fruits $(\bullet)$ at 20 $\pm 1^{\circ} \mathrm{C}$ and $85-90 \%$ relative humidity.

Effect on total soluble solids: Total soluble solids (TSS) progressively increased during ripening of both guava types. The maximum TSS value reached by untreated fruits was $14 \%$ in the white and $12 \%$ in the pink guavas. That maximum value was reached after 16 days in both types (Figs. $7 \& 8$ ). Ethrel and ethylene treatments differentially increased TSS in the two guava types. Fruits dipped in aqueous solutions of ethrel at 250, 500 and 1000 ppm, reached the maximum TSS value 2, 4 and 6 days earlier than the untreated fruits, respectively. While the fruits treated with ethylene released from ethrel reached that maximum value 6,7 and 9 days earlier at 250, 500 and $1000 \mathrm{ppm}$, respectively. Post-harvest treatments with ethylene or ethrel were reported to induce fruit ripening and increased TSS in bananas (Ibrahim et al., 1994), mangoes (Ashwani et al., 1995; Mohamed and Abu-Goukh, 2003) and oranges (El Rayes, 2000).

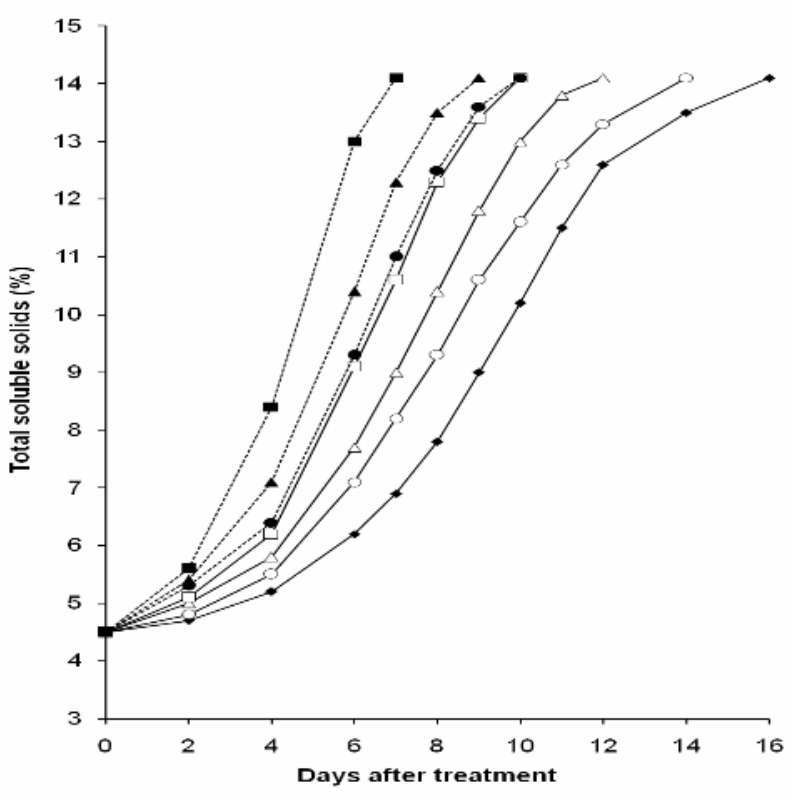

Fig. 7. Changes in total soluble solids during ripening of white guava fruits treated with ethrel in aqueous solution ( ) at 250 (o), $500(\Delta)$ and 1000 ppm ( $\square$ ) or with ethylene released from ethrel (------) at $250(\bullet), 500(\boldsymbol{\Delta})$ and $1000 \mathrm{ppm}(\mathbf{\square})$, compared with untreated fruits $(\diamond)$ at 20 $\pm 1^{\circ} \mathrm{C}$ and $85-90 \%$ relative humidity.

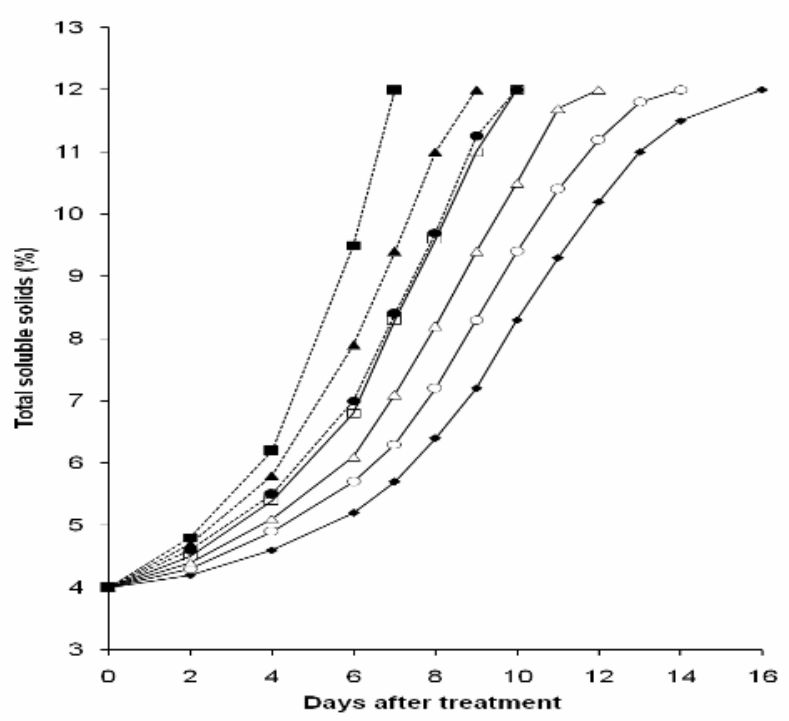

Fig. 8. Changes in total soluble solids during ripening of pink guava fruits treated with ethrel in aqueous solution (__ ) at 250 (o), $500(\Delta)$ and $1000 \mathrm{ppm}(\square)$ or with ethylene released from ethrel $(-----)$ at $250(\bullet), 500(\boldsymbol{\Delta})$ and $1000 \mathrm{ppm}(\boldsymbol{\bullet})$, compared with untreated fruits $(\bullet)$ at $20 \pm 1^{\circ} \mathrm{C}$ and $85-90 \%$ relative humidity. 


\section{CONCLUSION}

Ethrel in aqueous solution and ethylene released from ethrel in alkaline medium triggered fruit ripening in both guava types at all concentrations used. The usual method of applying ethrel to promote fruit ripening has the disadvantage of being applied in aqueous solution, an extra step in handling which increases cost and enhances the chances of spread of diseases. The technique of using ethylene released from ethrel in an alkaline medium, recommended in this study, is simple, easy, safe, less expensive and more effective than dipping fruits in aqueous solution of ethrel.

\section{REFERENCES}

Abu-Goukh, A. A. and Bashir, H. A. (2003). Changes in pectic enzymes and cellulase activity during guava fruit ripening. J Food Chem, 83(2): 213-218.

Ashwani, K.; Dhawan, S. S. and Kumar, A. (1995). Effect of post-harvest treatment on the enhancement of ripening of 'Dashehari' mango. Haryana J Hort Sci, 24(2): 109115.

Azab, S. and Ismail, A. (1994). Effect of ethrel on colour development and juice quality of sweet orange and grapefruits. Qatar Univ J Sci, 14(2): 293-297.

Bashir, H. A. (1999). Compositional and Enzymatic Changes during Guava Fruit Ripening. M Sc. (Agriculture) Thesis. University of Khartoum, Sudan.

Bashir, H.A. and Abu-Goukh, A.A. (2003). Compositional changes during guava fruit ripening. J Food Chem, 80(4): 213-218.

El Rayes, D. A. (2000). Enhancement of colour development and fruit ripening of 'Washington Navel' and 'Amoon'oranges by ethrel pre-harvest application. Assiut J Agric Sci, 31(2): 71-87.

Gomez, K. W. and Gomez, A. A. (1984). Statistical Procedures for Agricultural Research. $2^{\text {nd }}$ edition. John Wiley and Sons, Inc., New York, USA.

Ibrahim, K. E.; Abu-Goukh, A. A. and Yusuf, K. S. (1994). Use of ethylene, acetylene and ethrel on banana fruit ripening. Univ of Khartoum J Agric Sci, 2(1): 73-92.

Kader, A. A (2002). Postharvest Technology of Horticultural Crops. $3^{\text {rd }}$. edition Cooperative Extension, Division of Agriculture and Natural Resources, University of
California, Oakland, California. Publication 3311.pp 535

Lakshminarayana, S.; Subhiahshetty, M. and Krishnaprasad, C. A. (1975). Accelerated ripening of 'Alphonso' mango by application of ethrel. J Trop Sci, 17: 95-101.

Mohamed, H. E. and Abu-Goukh, A. A. (2003). Effect of ethrel in aqueous solution and ethylene released from ethrel on mango fruit ripening. J Hort Sci Biotechnol, 78(4): 568-573.

Pal, R. K. (1988). Ripening and theological properties of mango as influenced by ethrel and calcium carbide. Mysore J Food Sci Technol, 35(4): 358-60.

Pantastico, E. R. B.; Chattopadhyuy, T. K. and Subramanyam, H. (1975). Storage and Commercial Storage operations. In: Pantastico, Er. B. (Ed.). PostHarvest Physiology, Handling and Utilization of Tropical and Subtropical Fruits and Vegetables (pp. 314-318). AVI, West port, Connecticut, USA.

Pratt, H. K. \& Goeschl, J. D. (1969). Physiological roles of ethylene in plants. Annual Rev Plant Physiol 20: 541548.

Rao, V. N. M.; Shanmugavelu, K. G.; Srinivasan, C. and lah, D. R. P. (1971). Studies on the effect of ethrel (2chloroethyl phosphoric acid) on the ripening of fruits. South Indian Hort, 19: 1-8.

Rodrigues, R.; Agarwal, P. C. and Saha, N. K., (1971). Biochemical changes during development of 'Safeda' guava fruit. Indian Food Packer, 25(1): 5-20.

Russo, L. Jr.; Dostal, H. C. and Leopold, A. C. (1968). Chemical regulation of fruit ripening. Bioscience, 18: 109-116.

Stewart, I. and Wheaton, T. A. (1972). Carotenoids in citrus: Their accumulation induced by ethylene. J Agric Food Chem, 20: 448-449.

Thompson, A. K. and Seymour, G. B. (1982). Comparative effects of acetylene and ethylene gas initiation of banana ripening. Annuals of Applied Biol, 101: 407410.

Yamauchi, N.; Akiyama, Y.; Kako, S. and Hashinaga, F. (1997). Chlorophyll degradation in 'Wase Sabuma' mandarin (Citrus unshiu Marc.). Fruit on tree maturation and ethylene treatment. Scientia Horticulturae, 71(1-2): 35-42. 